\title{
Vasectomy in Pakistan: Changing culture of sharing responsibility towards better family health
}

\author{
${ }^{1}$ Sumaida Anwar ${ }^{2}$ Majid Shahzad \\ ${ }^{1}$ (Principal, Regional Training Institute Sahiwal, Population Welfare Department, Government of Punjab) \\ ${ }_{2}^{2}$ (PhD Fellow, Department of Anthropology, Quaid-I-Azam University Islamabad, Pakistan)
}

\begin{abstract}
The model study aims to improve the health of women's reproductive age by finding out the socioeconomic factors, which contribute towards vasectomy decision making and associated experiences of married couples in two districts of Southern Punjab Pakistan. For quantitative part 140 vasectomize males were interviewed. The mean age of sample was 38.7 years, 93.6\% respondents were satisfied with their decision and $92.9 \%$ had religious satisfaction on their choice of permanent contraception. In-depth interviews from couples for qualitative part revealed eight overarching reasons contributed towards vasectomy decision making and post vasectomy experiences depended on five factors i.e. attitude of service providers, post-operative recovery, sexual relationship, and effect on the health of husband and wife, and overall effect on family.
\end{abstract}

Keywords: Family Planning, Gender, Health Promotion, Responsiveness, Vasectomy

\section{Introduction}

Sterilization is the most pervasive and widely used contraceptive method in the world. According to ACQUIRE project report and as Pile envisions [1,2], it will remain the same for the next two decade. But it is the female sterilization which is fixed upon and preferred to vasectomy (i.e. permanent male contraceptive surgical method) without concurring that vasectomy is a boon. Its advantages are numerous it is quicker, much cheaper, suits to more settings and there is fast recovery according to John Hopkins Bloomberg School of Public Health [3]. As far as mortality is concerned, till now there is no documented mortality correlated to vasectomy while 10 to15 women die each year in America due to tubal ligation and the associated complications. Failure rate of vasectomy is around $1 \%$ and female sterilization is $2 \%$ according to Kathrine [4]. In developing countries like Pakistan, the chasm between vasectomy and tubal ligation is too wide to bridge as the prevalence of vasectomy is $0.1 \%$ and female sterilization is $8.2 \%$ - reported by Population Reference Bureau [5].

Throughout the world female is the main target group for family planning activities as discussed by Jagannadha [6]. Even if male contraceptive choices are available, health care providers devote little or no consideration to these procedures including vasectomy. This attitude no longer seems acceptable. Realization of this manager level ignorance towards issue resulted in male oriented activities to enhance the male involvement in reproductive health and family planning. Evidence from literature also indicates that men play prime role in family planning decision making and in determining the family size-a couple should have [7].

International agencies are investing mammoth amount in family planning programs. Developing countries family planning program predominantly depends on donor assistance but as donor assistance is expected to decline so main expenditure of services is likely to pass on to consumers [1]. In case of withdrawing of assistance, there is a need to promote cost effective methods of family planning. Vasectomy is safe, effective and cheaper, so the need is to make research and consider the factors which motivated these vasectomized males to opt vasectomy in family planning services. There is limited study on vasectomy in Pakistan. The identification and understanding of underlying factors leading to decision in favor of vasectomy and postvasectomy experiences are vital for future strategic planning to enhance male involvement in reproductive health and family planning and to create attitudinal shift from tubal-ligation to vasectomy.

\section{Methods}

A descriptive cross-sectional study carried out in Southern Punjab, Pakistan. It was a mixed model study having two elements i.e. quantitative and qualitative part. Sample:

140 vasectomized males were selected through simple convenient sampling for quantitative part. The vasectomized males included those who had vasectomy during 2005 to 2009 in Government sector settings i.e. in FHCs (Family Health Clinics) \& extension camps through FHC in marginalized, outreach rural areas of two districts of southern Punjab. For qualitative part, in-depth interviews were conducted from vasectomized couples, till saturation was secured. Drug addicts and those vasectomize males who had some chronic illness were excluded from study. 


\section{Data collection and analysis:}

Data was collected through structured questionnaire which was developed by keeping in view the objectives of study and probing the relevant national \& international literature. The variables included in structured questionnaire were explored through in-depth interviews of vasectomize males and their wives. The variables like sexual relationship after vasectomy which culturally and ethically could not be asked from males, were plumbed from better halves. Quantitative data entered and analyzed in SPSS version 17. Qualitative data was analyzed manually and factors affecting vasectomy decision making and post-vasectomy experiences were found out.

\section{Socio-economic characteristics of study respondents:}

\section{Results}

Mean age of respondents was $38.7 \pm 6 y$ yrs and $65 \%$ respondents lie in the age group 25 to 40 yrs. Formal education was lacking in $34.3 \%$ respondents while $8.5 \%$ were post graduates. Monthly income of the respondents varied from Rs 2500 /month to Rs 100,000 /month but the main bulk i.e. $45 \%$ respondents had monthly income between Rs 6000 to 10,000 /month. Among respondents $35.7 \%$ were earning their living on daily wages as unskilled workers. Socio-economic characteristics are reflected in Table.1.

Table.1: Socio-economic Characteristic of Study Respondents

\begin{tabular}{|l|l|l|}
\hline Age & Frequency & Percentage \\
\hline 25 to 40 yrs. & 91 & $65 \%$ \\
\hline 41 to 60 yrs. & 49 & $35 \%$ \\
\hline Education & 48 & $34.3 \%$ \\
\hline Illiterate & 44 & $31.4 \%$ \\
\hline Primary & 14 & $10 \%$ \\
\hline Middle & 22 & $15.7 \%$ \\
\hline Metric & 9 & $6.4 \%$ \\
\hline Graduate & 3 & $2.1 \%$ \\
\hline Post-graduate & 43 & $30.6 \%$ \\
\hline Monthly income in Pak Rs. & 63 & $45 \%$ \\
\hline 2500 to 5000 & 22 & $15.6 \%$ \\
\hline 6000 to 10,000 & 12 & $8.5 \%$ \\
\hline 11000 to 20,000 & \multicolumn{2}{|l|}{} \\
\hline Above 20,000 & 50 & $35.7 \%$ \\
\hline Profession & 44 & $31.4 \%$ \\
\hline Daily-wages Labor/Private job & 12 & $8.6 \%$ \\
\hline Land lord & 18 & $12.8 \%$ \\
\hline Farmer & 16 & $11.4 \%$ \\
\hline Govt. job &
\end{tabular}

SOURCE: FIELD DATA

\section{Qualitative Part:}

Overarching factors contributing towards vasectomy:

\section{1) Fear of side effects}

Slightly less than half of the total respondents had fear of side effects of temporary contraceptives and tubal-ligation. So they selected permanent contraception directly without trying temporary methods.

\section{2) Experience of side effects of temporary contraceptives}

Out of those who tried any temporary method, majority experienced side effects and failure of the procedures. Generally people avoid their use and prefer permanent methods.

\section{3) Financial constraints}

Majority of the respondents discussed financial constraint as contributing factor to opt vasectomy. Few of the respondents accepted vasectomy when they were only 25 yrs old and their wives were in early 20s. One of them had two kids under 5, and other one had three kids, out of these two were below 5. Both of these respondents had deliveries through cesarean section and they financially could not afford another cesarean section. They didn't try any temporary method just because of fear of side effects of temporary contraceptives and directly jumped to permanent contraception. One of the respondents could not even meet the basic needs of the children how could he think of other things like marrying his elder daughter. Another respondent (A satisfied client, who also motivated 35 clients) replied enthusiastically, though he was untutored but he wanted to enlighten his children. He decided for vasectomy because he wanted better life for his children within limited financial resources. 


\title{
4) Satisfied clients of vasectomy
}

Satisfied clients of vasectomy affect the acceptability of vasectomy. A reasonable number of respondents accepted this method after meeting with satisfied clients or watching T.V interview of Dr. Abdul Qadeer Khan (Pakistani Nuclear Scientist) who is also one of the satisfied clients of vasectomy.

\section{5) Medical ground}

Medical ground included both the tubal-ligation contraindicated and high risk pregnancy. In few of the respondents tubal- ligation was contraindicated. While in some other respondents, further pregnancy could be high risk, so these couples received medical advice for permanent contraception. Male partners of such families realizing their family health shouldered the burden of contraception.

\section{6) Mutual decision}

The majority of respondents who decided after having mutual discussion were confident. There were fewer who had to take step individually due to certain reasons. They were also not repentant.

\section{7) Male dominance}

Whether vasectomy or sterilization, the decision power is with male. Majority of them is naïve so fewer who opts vasectomy are really considerate.

\section{8) Religious belief}

Religious beliefs and doubts about permanent contraception affect the decision making in all the respondents. Some of them also seek religious advice before opting vasectomy. The respondents admitted that they didn't have enough religious knowledge to decide about permanent contraception. Majority of the respondents including illiterate to post graduate have sound decision while few highly educated respondents have serious religious doubts and they demanded clear religious guidance.

\author{
Post-vasectomy experiences depended on: \\ 1) Attitude of service providers \\ 2) Post-operative recovery \\ 3) Sexual relationship \\ 4) Effect on personal health of husband and wife \\ 5) Effect on family \\ 6) Mutual decision
}

On the basis of post vasectomy experiences, Respondents were divided into two main groups:

\section{1) Satisfied clients}

Satisfaction relies on the care, co-operation and friendly attitude of the service providers. Postoperative facilitation of the client in the form of free medication helps in early recovery. Whereas postcontraceptive satisfaction depends on the health of husband/ wife, care of children and healthy sexual relationship. In case of vasectomy majority of the respondents were satiate with the decision.

\section{2) Un-satisfied clients}

Non- satisfied clients have their causes, though they were fewer but the causes were genuine. The contributing factors were the attitude of the service providers and lack of post-operative care. That affected the family adversely. Disruption of sexual relationship and aching miserable life changed the peaceful and calm and quiet life into hell. Service providers never cared for them. There were no follow up visits and no provision of free medicine. All this not only affected the reputation of the service providers but also annoyed many others to reject it.

\section{Quantitative Part:}

\section{1) Number of children and years of marriage of study population}

The years of marital life passed at the time of vasectomy of the study population were 5 years to 33 years, with the mean value was 15.5 years \pm 5.0 years. The total number of children per family was 2 to 12 ; with mean number of total children were $5.5 \pm 2$.

Numbers of living sons of 140 vasectomize males were 1 to 8 , with mean value were 3 . Out of 140 respondents eight $(5.7 \%)$ vasectomies males had no daughter as shown by Table 2 but no one was without son perhaps reflecting the son preference in our society. 
Table.2: No. of Children and Years of Marriage at the Time of Decision

\begin{tabular}{|l|l|l|l|}
\hline No. of children & Frequency & Percentage & Mean \\
\hline No. of Sons & & & $\mathbf{3}$ \\
\hline 1 to 3 sons & 101 & $72.2 \%$ & \\
\hline 4 to 6 sons & 34 & $24.4 \%$ & \\
\hline Above 6 & 5 & $3.6 \%$ & \\
\hline No. of daughters & & & $\mathbf{2 . 5}$ \\
\hline With no daughter & 8 & $5.7 \%$ & \\
\hline 1 to 3 daughters & 100 & $71.5 \%$ & \\
\hline 4 to 6 daughters & 29 & $20.7 \%$ & \\
\hline Above 6 & 3 & $2.1 \%$ & \\
\hline Total children & & & $\mathbf{5 . 5}$ \\
\hline 2 to3 children & 23 & $16.4 \%$ & \\
\hline 4 to 5 children & 54 & $38.6 \%$ & \\
\hline 6 to 7 & 37 & $26.4 \%$ & \\
\hline Above 7 & 26 & $18.6 \%$ & \\
\hline $\begin{array}{l}\text { Years of marriage at the } \\
\text { time of vasectomy }\end{array}$ & & & $\mathbf{1 5 . 5}$ yrs. \\
\hline 4 to 10 yrs. & 24 & $17.2 \%$ & \\
\hline 11 to 15 yrs. & 47 & $33.7 \%$ & \\
\hline 16 to 20 yrs. & 54 & $38.5 \%$ & \\
\hline 21 to 25 yrs. & 11 & $7.8 \%$ & \\
\hline Above 25 yrs. & 4 & $2.8 \%$ & \\
\hline SOURCE FIELD DATA & & & \\
\hline
\end{tabular}

SOURCE: FIELD DATA

2) Source of information about vasectomy, distance covered and time spent to get services

Male mobilizers of Population Welfare Department were the main source of providing information about vasectomy. Eighty seven respondents $(62.1 \%)$ got information including motivation from these male mobilizers. Usually respondents got information from multiple sources. Vasectomy services are available in FHC Bahawalpur on daily basis. On behalf of Government, only one doctor is responsible to provide vasectomy services in three districts of southern Punjab through extension camps. Camping practice is not on regular basis. Waiting time is longer for those who are operated on camps. Seventy nine respondents (56.4\%) tried temporary contraceptives before deciding for vasectomy. CU-T was the most common contraceptive among respondents.

Table.3: Source of Information and Use of Temporary Contraceptives by Respondents

\begin{tabular}{|l|l|l|}
\hline Source of Information & Frequency & Percentages \\
\hline By male mobilisers & 87 & $62.1 \%$ \\
\hline Satisfied clients & 22 & $14.3 \%$ \\
\hline Partner & 14 & $10 \%$ \\
\hline Other service providers & 17 & $12.1 \%$ \\
\hline By multiple sources & 67 & $46.8 \%$ \\
\hline Temporary contraceptives used & 24 & $17.1 \%$ \\
\hline CU-T & 11 & $7.8 \%$ \\
\hline Hormonal injections & 9 & $6.4 \%$ \\
\hline Oral pills & 16 & $11.4 \%$ \\
\hline Condoms & 19 & $13.6 \%$ \\
\hline Multiple methods used & 79 & 56.4 \\
\hline Tried any method & 61 & $43.6 \%$ \\
\hline Never used any method & \multicolumn{2}{|l|}{} \\
\hline SOURCE: FIELD DATA &
\end{tabular}

\section{3) Level of satisfaction, spousal role and effect on family}

Out of 140 respondents, one hundred and thirty-one respondents (93.6\%) were satisfied while seven (5\%) were dis-satisfied with their decision. Religiously one hundred- thirty $(92.9 \%)$ have sound decision and ten $(7.1 \%)$ have serious doubts. One hundred- sixteen $(82.9 \%)$ have discussed the matter with their wives and did mutual decision while twenty four $(17.1 \%)$ decided individually without discussing with their wives. One hundred and Twenty one (86.4\%) felt good effects of the decision on their family.

Table. 4: Satisfaction of Respondents, Spousal Role and Effect of Decision on Other Families

\begin{tabular}{|l|l|l|}
\hline Satisfaction with the decision & Frequency & percentages \\
\hline Satisfied & 133 & $95 \%$ \\
\hline Dis-satisfied & 7 & $5 \%$ \\
\hline Religious satisfaction & 130 & $92.9 \%$ \\
\hline Sound decision & 10 & $7.1 \%$ \\
\hline Doubts & \multicolumn{2}{|l|}{} \\
\hline Spousal role
\end{tabular}




\begin{tabular}{|l|l|l|}
\hline Joint decision & 116 & $82.9 \%$ \\
\hline Individual decision & 24 & $17.1 \%$ \\
\hline Effect on family & 121 & $86.4 \%$ \\
\hline Good & 9 & $6.4 \%$ \\
\hline Bad & 10 & $7.1 \%$ \\
\hline Neither good nor bad & \multicolumn{2}{|l|}{} \\
\hline
\end{tabular}

SOURCE: FIELD DATA

\section{Discussion}

This study is an attempt to identify the factors leading to decision in favor of vasectomy and post vasectomy experiences of vasectomized males and their wives. Socio-economic characteristics of studied population showed that main bulk of respondents were from the younger age group. The mean age of the sample was 38.72 years. This mean age is somewhat higher to the findings of other studies done outside Pakistan and also higher to the findings of a study (mean age 36.13 years) done in Pakistan in 2005 on males visiting the hospital for vasectomy [8]. This study shows that some of the respondents accepted the method when they were in age group of 25 years and their wives were in early twenties, and 2/3rd respondents were in age group 25 to 40 years, which reflected that majority of respondents accepted the method in younger age. The underlying reason may be fear \& experience of side effects of temporary contraceptives [9], financial constraints and may be on medical grounds.

Two of the respondents accepted the method because they could not afford financially 3rd and 4th cesarean section. The acceptance of permanent contraception in very young age along with kids less than five years of age may lead to regrets about surgery in the long run as is evident from international literature [10]. One-third of the study sample was illiterate compared to previous study in Pakistan in 2005 in which 62\% sample was illiterate. One-third sample had primary education. Sample population also included graduates and post graduates. Studied population had wide range of monthly income but the main bulk i-e $45 \%$ had earning between Rs. 6000 to 10,000/ month. It manifests that vasectomy is not only the choice of the poor and illiterate but also agreeable for the rich, graduates and post graduates. People from different walks of life accepted the method and there was no preference of any working group, average number of children per family who accepted vasectomy was also high [11], compared to current national fertility rate, but international literature reveals that those who accepted the vasectomy have smaller families as compared to those who incline to tubal ligation [12], still we do not have any such comparison at national level. There was no one without a son, a finding consistent to previous National study conducted in 2005 while reasonable proportion of respondents were without daughter, that is also cultural preferences in the society.

The sensitivity of the issue and the careful attitude of the respondents are obvious from the fact that they got information about vasectomy from multiple sources before taking decision. The motivation sources were male mobilizers of Population Welfare Department, satisfied clients, and the friends. Service providers and satisfied clients are the major source of information and motivation, so accurate knowledge and updated information is particularly important to promote the method.

The distance covered and the time taken reflects from where the services are obtained. The studied districts were covered through extension camps organized by Population Welfare Department. If the services provided for vasectomy are compared to that provided for tubal-ligation, it becomes clear that both the services are through extension camps. The camp for tubal-ligation in outreach areas is conducted monthly by Population Welfare Department on regular basis whereas there is no regular camping for vasectomy. Lack of regular services may be the contributing factor towards low prevalence of vasectomy. This is realized by Bangladesh government in 2008, and they took step for regular outreach services and achieved good results [13], in Pakistan services on daily basis were available only in one city in three districts.

Less than half of the sample respondents never tried any temporary method before going for permanent contraception and the underlying reason may be the fear of side effects of temporary contraceptives. This may be the contributing factor in decreasing CPR of the country, and results in acceptance of permanent contraception at very young age with children less than five years. Most common temporary method was CU-T. In most cases, the reason for switching over to permanent contraception may be the experience of severe side effects of temporary contraceptives or the method failure.

Up-to-date knowledge of contraception among men is a basic prerequisite to guide them to the adoption of contraceptive use. All the respondents have different level of knowledge about available contraceptives, mostly detailed knowledge was lacking, but there was no one who did not know the name of any method. This finding is in consistent with Ministry of Population Welfare claim that the knowledge about contraceptive methods is $98 \%$.

Most of the respondents decided for permanent contraception because they were satisfied with the size of the family, financial constraints contributed in more than $90 \%$ cases, a finding that confirms economic 
reasons leading to decision of vasectomy inferred from previous studies done in Sri-Lanka, Bangladesh and Tanzania [14].

Respondents render different reasons for accepting vasectomy over tubal-ligation, which reflects their sense of responsibility and health concerns to their wives and positive attitude towards improved quality of life which is in consistent with other studies outside the country [9]. At some places vasectomy was preferable just because of its advantages, so promulgating the benefits of vasectomy may be helpful in creating the attitudinal shift from tubal ligation to vasectomy.

Attitude of service providers have strong effect in creating satisfied clients, most of the respondents were quite satisfied with the service provider's attitude but those who developed some complications were extremely dis-satisfied because of non-provision of follow up services. Usually service providers ignore those clients who develop complications.

While sharing post vasectomy experiences, more than $93 \%$ respondents were satisfied with their decision and finding is consistent with other international studies. The satisfied respondents were mentally relaxed and their wives felt improvement in health. The decision provided them opportunity for better care of kids.

The reason behind the un-satisfied clients was the development of complications. This may be due to the lack of follow up visits from service providers and lack of guidance whom should the clients contact in case of complications.

Families of the un-satisfied clients faced lot of problems and they their lives were almost destroyed. Although their number was negligible but they were the cause of demotivation for the community. These unsatisfied clients might be the source of discouragement for others, creating misconceptions so reducing the acceptability of vasectomy. With current negligible prevalence of vasectomy, these cases may be taken into account by the department.

Religiously people have different views, $93 \%$ were satisfied religiously. These include those who took advise from religious persons before decision while some were ignorant about religious orders moreover financial constraints overcame religion.7\% respondents have very serious doubts and felt regrets just because of these doubts and wanted clear cut religious instructions in this issue, otherwise they were extremely satisfied. This finding is in contrast to a study in Ethiopia which shows that impact of religion on contraceptive use now diminished and this might be underlying reason of low vasectomy prevalence in educated sensible community. Although service providers claim that it is allowed religiously but their knowledge was deficient.

Husbands and wives communication has positive effect on contraceptive use and decision making about vasectomy as evidenced by national and international research findings $[9,10]$. This joint decision making further results in higher satisfaction level [15] as evidenced in this study. $82.9 \%$ of the respondents who discussed matter with their wives before taking any decision and most of them not only discussed with wives but also to other family members in contrast to previous study conducted in 2005 , where only $76 \%$ consulted their wives. A positive role of women in decision of vasectomy has also been reported in other countries (factors associated with the acceptance of vasectomy in Tanzania). Only 17.1\% had individual decision for which they have different reasons.

Almost all the wives of vasectomized males claimed that there were no adverse health effects on their husbands, a finding [16] consistent with lot of international and national literature while $13 \%$ claimed that their husband's health even improved after surgery.

Most of the wives explained that their sexual relationships were exactly the same as before, a finding again according to international literature but $20 \%$ complained of sexual weakness.

\section{Conclusion}

This study shows the gradual change in the attitude of the people and their cognizance of the word vasectomy. Satiate clients can act as role model and an important source of motivation in sensitive issues like vasectomy. Perception will oust the rumors through satisfied clients and vasectomy will be no longer unacceptable in Pakistani Society.

\section{Ethical Standards}

This study was conducted after getting approval from the Institutional Ethical Review Committee and after obtaining written consents from all respondents.

Source of funding: The authors did not receive any financial support from any third party related to the submitted work.

Conflict of interest: The authors had no relationship/condition/circumstances that present a potential conflict of interest.

(Correspondence to Shahzad M: majidshahzadc@gmail.com) 


\section{References}

[1] John M. Pile, Vasectomy Advocacy Package: Safe, Cost-Effective, and Underutilized. Advocacy Brief No. 5. 2004

[2] Family Health International, Engender Health, ACQUIRE Project, Experts Consultation on Vasectomy. Meeting Report. Washington D.C. 2003

[3] John Hopkins Bloomberg School of Public Health. Vasectomy: Reaching out to New Users. Population Reports. 2008

[4] B. Katherine, Vasectomy-The Phacts and Phallacies. Women Health. 2006

[5] Population Reference Bureau. 2008

[6] R.A. Jagannadha, A Holistic Approach to Population Control in India. Indian Institute of Science. Bangalore, India. 2001

[7] M. Farrokh, M.H. Amir, A. Homa, Socio-Cultural Factors Affecting Men's Use of Family Planning Methods in Iran. Journal of Social Sciences \& Humanities of Shiraz University, Vol; 24 No: 2, 2006

[8] A. Shabana, R. Amjad, C. Haroon Rashid, Psychosocial Factors and Male Sterilization. Pakistan Journal of Medical Sciences. Vol; 22 No. 3, 2006

[9] W. Abraham, A. Adamu, D. Deresse. The Involvement of Men in Family Planning: An Application of Tran Theoretical Model in Wolaita Soddo Town South Ethiopia. Asian Journal of Medical Sciences 2(2): 44-50, 2010

[10] T. Tsedeke, D. Wakgari, A. Ahmed, D. Gail, The Role of Men in Contraceptive Use and Fertility Preferences in Hossana Town, Southern Ethiopia. Addis Ababa University

[11] M. Framurzk, Motivation and Involvement of Men in FP in Pakistan. The Pakistan Development Review, 2003

[12] C. Suzannel, Vasectomy \& National FP Program in Asia and Latin America. Department of Maternal and Child Health, School of Public Health

[13] MARIE STOPES International, Marie Stops Vasectomy: Expanding Access in Bangladesh. 2010

[14] B. Arwen, et al. Factors Affecting Vasectomy Acceptability in Tanzania, International Family Planning Perspectives. Volume 33, Number 1, March 2007

[15] H. Armen, Non-scalpel Vasectomy by Skilled Surgeons may speed recovery. E-Max Health. 2007

[16] The ACQUIRE Project/Engender Health, Get a Permanent Smile- Increasing Awareness of, Access to, and Utilization of Vasectomy Services in Ghana. 2005 